\title{
The impact of mass customisation practices on performances: an exploratory study of Chinese manufacturers
}

\author{
Min Zhang \\ Nottingham University Business School, \\ The University of Nottingham, \\ Jubilee Campus, Wollaton Road, Nottingham, UK \\ E-mail: min.zhang@nottingham.ac.uk

\section{Yinan Qi*} \\ School of Business, \\ University of International Business and Economics, \\ No. 10, Huixin Dongjie, Chaoyang District, Beijing, China \\ E-mail: yinanqi@gmail.com \\ *Corresponding author
}

\section{Xiande Zhao}

Department of Decision Sciences and Managerial Economics, The Chinese University of Hong Kong,

No. 12, Chak Cheung Street, Shatin, N.T., Hong Kong

E-mail: xiande@baf.msmail.cuhk.edu.hk

\begin{abstract}
Using a large-scale survey in China, this study identifies a set of manufacturing practices based on the framework proposed by Zipkin (2001), and builds and tests a model describing the relationship between mass customisation practices and firm performances. The results demonstrate that the mass customisation practices can bring benefits to manufacturers in terms of both cost reduction and product/service quality improvement, which in turn boost financial performance. Moreover, we find that the practices of elicitation, flexibility in design, advanced manufacturing technology (AMT), just-in-time (JIT) supply chain and integrated logistics information system (ILIS) play different roles in business performance improvement. To be specific, the elicitation and ILIS are very important to operational performance in terms of cost and product/service quality. The flexibility in design and AMT are beneficial to cost reduction only. However, the JIT supply chain has no impact on neither cost nor product/service quality in China.
\end{abstract}

Keywords: China; mass customisation; operational performance; financial performance.

Reference to this paper should be made as follows: Zhang, M., Qi, Y. and Zhao, X. (2011) 'The impact of mass customisation practices on performances: an exploratory study of Chinese manufacturers', Int. J. Mass Customisation, Vol. 4, Nos. 1/2, pp.44-66. 
Biographical notes: Min Zhang is a Research Fellow in Nottingham University Business School of The University of Nottingham. He received his $\mathrm{PhD}$ in Operations Management from The Chinese University of Hong Kong. $\mathrm{He}$ has been published several journal articles in publications including International Journal of Production Economics and International Journal of Physical Distribution and Logistics Management.

Yinan Qi is an Associate Professor of Operations Management at the School of Business of University of International Business and Economics. He is also the Director of Centre for International Business Case. He received his $\mathrm{PhD}$ in Operations Management from The Chinese University of Hong Kong. He joined the University of International Business and Economics in 2006. He has taught courses on operations management and supply chain management. $\mathrm{He}$ has been published several journal articles in publications including Journal of Operations Management, International Journal of Operations and Production Management and Decision Sciences.

Xiande Zhao is a Professor of Operations Management in the Department of Decision Sciences and Managerial Economics and Director of the Center for Supply Chain Management and Logistics, Li and Fung Institute of Supply Chain Management and Logistics, The Chinese University of Hong Kong. He received his $\mathrm{PhD}$ in Operations Management and a minor in International Business at the University of Utah. He has published more than 50 journal articles in Journal of Operations Management, Production and Operations Management, Journal of Consumer Research, and International Journal of Production Research. He is an Associate Editor of the Journal of Operations Management, Decision Sciences, Operations Management Research, and International Journal of Business and Systems.

\section{Introduction}

Mass customisation (MC) refers to the strategy of delivering product/service in response to particular customers' needs with near mass production efficiency (Pine, 1993). There are empirical evidences that MC capability comes from product related practices (Tu et al., 2004; Duray et al., 2000), process related practices (Tu et al., 2004, 2001; Duray et al., 2000; Liu et al., 2006; Huang et al., 2008), and supply chain related practices (Tu et al., 2001; Huang et al., 2008). These studies emphasise on different aspects of the manufacturing system by applying various theoretical frameworks and models. However, through in-depth case studies of the successful mass customisers, researchers have found that $\mathrm{MC}$ requires the manufacturers to redesign the whole manufacturing system that includes product, process, and supply chain practices (Pine, 1993; Feitzinger and Lee, 1997; Rungtusanatham and Salvador, 2008). While some studies (Zipkin, 2001; Berman, 2002; Pine, 1993) conceptually describe integrated MC system, the empirical evidences are very limited. In addition, $\mathrm{MC}$ has frequently been described as an 'ideal state' in practice and managers tend to view it as an impractical idea (Salvador et al., 2009). Moreover, despite of the increasing research interests on how to build MC capability, the empirical researches on the link between MC practices and performance, which is the key measure of success for all business decisions, are still fragmented and anecdotal (Duray, 2006). Some researchers believed that MC improves manufacturers' performance (Pine, 1993; Duray, 2006; Feitzinger and Lee, 1997), others 
have proposed that the variety and complexity associated with $\mathrm{MC}$ operations might endanger the success of the company (Ahlstrom and Westbrook, 1999). Therefore, there is a need to investigate the MC system in terms of practices and empirically test the relationship between MC practices and firm performance. This will help practitioners to link MC with a distinctive set of practices and understand how to benefit from MC implementation (Piller, 2004; Salvador et al., 2009).

China has become a world factory and plays a significant role in global supply chains (Zhao et al., 2007). The conventional wisdom is that Chinese manufacturers compete mainly through low cost. However, the high performing manufacturing project, which aims at comprehensively examining the phenomenon of world-class manufacturing globally (Schroeder and Flynn, 2001), showed that Chinese manufacturers started to recognise the importance of fast response to non-standard orders, short manufacturing cycle time, and rapid customisation of orders. Moreover, the history and economic environment determines that Chinese manufacturers do not have enough knowledge and skill accumulation to catch up with their abroad counterparts in terms of technical innovations. Thus, the majority of them are just copying foreign competitors' products, developing new applications of existing technologies, and designing for the local supply chain, which means they mainly innovate through customising for the market. Furthermore, the managers also pay a lot of attentions to control the cost associated with customisation because they are facing pressures from both the increasing materials and labour cost and decreasing market price. Therefore, many Chinese manufacturers have to transition from mass production to MC (Piller, 2005).

For example, Youngor, one of the largest Chinese apparel manufacturers, dedicated $15 \%$ of its total capacity to produce mass customised suits (Piller, 2005). Haier, the world's fourth largest electrical appliance manufacturer, implemented its MC programme called 'My Refrigerator, My Design' in 2000 (Zhang and Ju, 2002). Now, more than half of the total number of refrigerators is mass customised. Luen Thai ${ }^{1}$, an apparel manufacturer, launched the 'design to shop (D2S)' business model and reengineered the entire production system and supply chain to implement MC. Zhang and Chen (2006) also reported that many Chinese manufacturers in the automobile industry have transitioned their operations by applying MC. In addition, through a field study of Chinese manufacturers, we observed that they are aware of the importance of MC practices, but a systematic implementation is not yet the norm. Therefore, China provides us a good case to explore MC practices since they might follow a different path to MC comparing with western companies. The main objectives of this paper are to identify the $\mathrm{MC}$ practices using a systematic perspective and investigate the impact of $\mathrm{MC}$ practices on firms' operational and financial performance.

\section{Theoretical background and hypotheses}

\subsection{MC practices}

Zipkin (2001) and Berman (2002) provided a very comprehensible method to conceptualise the MC system. They identified a set of manufacturing practices (elicitation, process flexibility technology, and logistics) that cover the whole procedure of market analysis, product/process design, production, and delivery. 
Elicitation is "a mechanism for interacting with the customer and obtaining specific information" [Zipkin, (2001), p.82]. Manufacturers need an information system to acquire their customers' preferences. Information technology (e.g., internet and web-based toolkits) has greatly facilitated this communication process (Da Silveira et al., 2001). However, customers might be overwhelmed by the variants of offerings and thus become unsure about what they really want. In order to make the elicitation work, manufacturers also need to share information with customers. This can help them better understand what manufacturer can offer and build a trustworthy relationship. Therefore, through elicitation, the interaction between customers and manufacturers can help the latter determine what really suits customers' demands, which can greatly improve the product and process design.

Process flexibility technology is the "production technology that fabricates the product according to the information" [Zipkin, (2001), p.82]. Berman (2002) explained that such technology comprises flexibility in both design and manufacturing processes. Flexibility in design includes postponement and supply chain co-design, which have been identified as the key practices for improving the product and process design (Berman, 2002). Through combining modularity in product and process design to delay product finalisation, postponement has been viewed as a practical method in moving towards MC (Feitzinger and Lee, 1997). Co-design means involving suppliers and customers' voices in the new product development process (Piller, 2004). Flexibility in manufacturing process mainly refers to the application of advanced manufacturing technologies (AMTs), which automates the production activities (Berman, 2002; Da Silveira et al., 2001). Such technologies have been widely used in the design, production, and planning processes to support MC (Pine, 1993).

Logistics is the "subsequent processing stages and distribution that are able to maintain the identity of each item and to deliver the right one to the right customer" [Zipkin, (2001), p.82]. Berman (2002) further explained that a logistics system requires two kinds of practices: a highly coordinated supply chain, which is represented by the application of the just-in-time (JIT) supply chain, and an integrated logistics information system (ILIS) that connects raw material management, production, shipping, and sales in real-time. The application of the JIT supply chain assists the manufacturer to reduce the waste in terms of cost and lead-time across the supply chain. An advanced information system is a pre-requisite to implement MC (Pine, 1993; Da Silveira et al., 2001). Information technology should be used to coordinate information flow in the existing systems (e.g., planning, inventory, logistics, and product design) to support MC (Sugumaran et al., 2006). These tools help the manufacturer integrate and coordinate information from different sources to support intra-organisational cooperation and collaboration. Thus, these two practices can help the manufacturer to redesign the supply chain for MC.

These practices can build such capabilities demanded by $\mathrm{MC}$ as solution space development, robust process design, and choice navigation (Salvador et al., 2009). In particular, elicitation can not only acquire "product attributes along which customer needs diverge" but also "support customers to identify their own solutions while minimising complexity and the burden of choice" through interacting with customers, sharing information with them, and obtaining their information and preferences quickly and accurately [Salvador et al., (2009), p.73]. The practices of process flexibility technology and logistics can integrate "organizational and value chain resources to fulfil a stream of differentiated customers' needs" through automating internal operations and 
improving the effectiveness and agility of the supply chain [Salvador et al., (2009), p.73]. As a matter of fact, such a framework is also implemented by successful mass customisers (Berman, 2002). For instance, Luen $\mathrm{Thai}^{2}$ established fashion design workshops in New York, New Jersey, Hong Kong, and London, which helped them not only keep abreast of the world fashion developments but also facilitate customer interaction and gain first-hand information about customers' demand (elicitation). In the supply chain city in Dongguan (a city located in southern China), Luen Thai employed modular mode of production and invested a lot on the AMTs, such as ERP software package (GO2000) and computer aided design software (Gerber) (process flexibility technology). With the assistant of information systems, such as supply chain management software packages (xo Track, ec Track, ee Track), fabric transportation and advance shipment notice system (ASN XFAB), product tracking system (Pro Track), and warehouse tracking system (Wear Track), Luen Thai also developed an integrated supply chain that can deliver goods directly to designated location like stores or warehouses around the world (logistics). Hence, Zipkin's framework provides us a suitable way to model the elements of MC system.

\subsection{Impact of MC practices on operational performance}

In the global supply chain, the Chinese manufacturers gain competitive advantages through low cost advantage. However, the increasing cost is one of the most important threats for MC (Ahlstrom and Westbrook, 1999). Thus, operational cost is an important criterion for evaluating Chinese manufacturers' MC success. On the other hand, there are many product failures and safety issues of Chinese manufacturers' exported products recently (e.g., the toy industry), which cause a lot of concerns of the product quality in the global market. Nowadays, both Chinese manufacturers and overseas customers believe the quality is another critical criterion for assessing Chinese manufacturers' operations. Furthermore, the product customisation should be provided without tradeoffs in quality and the quality of the customised products/service directly determines how much premium customers would like to pay for customisation (Liu et al., 2006; Piller, 2004). Therefore, both cost and product/service quality are used to appraise the success of MC practices.

\subsubsection{Elicitation}

As an interface between manufacturer and customer, elicitation aims at understanding what customers really want and uncovering something that customers themselves have not realised. Piller and Muller (2004) suggested a customer perspective of MC, which proposed that the MC solution space should be defined by three pillars: the differentiation option, the cost option, and the relationship option. With the help of information technology and customer relationship management techniques, elicitation can help manufacturers find the degree of customisation of consumers' demand (differentiation option), how much they want to pay for the customisation (cost option), and the feedback of past purchasing experiences (relationship option). Such information can assist manufacturers in modifying their internal manufacturing and logistics processes to develop the best MC solutions that fit the customers' demands. Moreover, timely information sharing with customers speeds up decision making and often results in shorter lead-time. Based on this information, the manufacturers can fit the product with 
customers' requirements better, which not only reduce the production cost but also improve the product/service quality.

Therefore, we propose the following hypotheses:

H1 The application of elicitation practices has a positive impact on a firm's operational performance in terms of cost.

H2 The application of elicitation practices has a positive impact on a firm's operational performance in terms product/service quality.

\subsubsection{Process flexibility technology}

One purpose of postponement and co-design is to design the product and process so that finalisation can be delayed until the customers' orders are received. Researchers have found that postponement can reduce inventory-related cost (Feitzinger and Lee, 1997). Yang et al. (2005) also revealed the significant and positive relationship between postponement and firm's operational performance. Piller (2004) argued that co-design is an important approach to improve design efficiency and to pave the way for several cost-saving potentials. Moreover, acknowledging partners' suggestions on product design will accelerate the development process, and improve project effectiveness and design performance (Petersen et al., 2005). So, the application of flexibility in design practices not only enable manufacturers to aggregate the parts production, which reduces the unit cost, but also substitute finished goods by semi-finished ones, which are much cheaper. Some researchers argue that these design practices can reduce cost without sacrificing quality (Feitzinger and Lee, 1997). Moreover, through improving the flexibility of product and process design, customers can feel manufacturers' efforts by receiving higher degree of customisation. Thus, manufacturers can improve customer's perceived quality level since the product and production fit their requirements better. Furthermore, incorporating customer information and suppliers' suggestions into product design can match the demand with product better, which increases the conformance and performance quality of the product/service.

Therefore, we propose the following hypotheses:

H3 The application of flexibility in design has a positive impact on a firm's operational performance in terms of cost.

H4 The application of flexibility in design has a positive impact on a firm's operational performance in terms of product/service quality.

The AMT aims at automating and optimising the designing, planning, and producing activities. As one of the main enabling technologies for MC (Da Silveira et al., 2001), the $\mathrm{CAE} / \mathrm{CAD}$ integrates customers' information into the design process; the CAM/CNC takes the responsibility to apply the design into the production; and the ERP schedules the whole process and ensures that required equipments and materials are accessible when needed. In this way, the AMTs can greatly improve manufacturing process flexibility and productivity, which reduce unit and inventory-related costs. Safizadeh et al. (1996) reported that AMT can help manufacturers compete by enabling them to produce customised products at mass production cost. Therefore, AMT enables firms to pursue volume efficiency and product flexibility at the same time. It also aims at facilitating collaboration between product and process designers as they seek to make the 
most effective use of manufacturing technologies and using connected line flow. McDermott and Stock (1999) found that AMT brings operational benefits and improvements in productivity and flexibility to the company. These internal efforts and improvements enable the manufacturers to fit the products with customers' demands better. From the customers' perspective, this can improve quality level they received. So, companies' internal manufacturing flexibility and productivity contribute to the quality improvement since they ensure customers can get their desired products on time. Thus, the application of AMT also significantly improves product/service quality.

Therefore, we propose the following hypotheses:

H5 The application of AMT has a positive impact on a firm's operational performance in terms of cost.

H6 The application of AMT has a positive impact on a firm's operational performance in terms of product/service quality.

\subsubsection{Logistics}

Successful JIT implementation accomplishes two major objectives: improving quality and controlling the timeliness of production and delivery of products (Fullerton and McWatters, 2001). The tenet of JIT is to reduce waste during the whole production process. Thus, redesigning the supply chain based on JIT principles can decrease the operating cost across the supply chain and improve efficiency. Both the supplier and the buyer can enjoy logistics cost reduction through the application of JIT purchasing. Thus, companies that have implemented JIT systems will enjoy better manufacturing performance and are able to bring products to the market faster. Meanwhile, the JIT supply chain can also improve the product quality since it helps the manufacturers reduce the waste that does not bring value to customers, which enables them to put more resources to improve the degree of customisation. Moreover, the JIT supply chain can also reduce the lead-time and achieve quick response to customers, which helps the manufacturers serve the customer better. For example, Fullerton and McWatters (2001) indicated that managers adopting JIT practices experience considerable benefits in many areas such as quality improvements, time-based responsiveness, employee flexibility, accounting simplification, firm profitability, and inventory reductions. From both cross-sectional and longitudinal perspectives, Fullerton et al. (2003) found the significant statistical relationships between the implementation of JIT systems and firm performance.

An efficient logistics and transportation system is the basis for the successful implementation of the JIT practices. Though underdeveloped logistics infrastructure in China has created barriers and challenges, due to the rapid economic growth and enormous demand, the logistics market has grown very quickly and many experienced third-party logistics (3PL) providers entered the marketplace to offer high standard services to the manufacturers after China opened up logistics market in accordance with the terms of World Trade Organization (Lai et al., 2008). An increasing number of companies are outsourcing their logistics activities to 3PL providers to improve their operational performances (Lai et al., 2008). In addition, the government has invested a lot in improving logistics system, especially in the areas of Pearl River Delta (PRD), Yangtze River Delta (YRD), and Bohai Sea Rim (BSR) (Zhao et al., 2007). Hence, we 
argue that though China has relatively poor infrastructure at the moment, manufacturers are still able to use JIT supply chain and benefit from its implementation.

Therefore, we propose the following hypotheses:

H7 The application of the JIT supply chain has a positive impact on a firm's operational performance in terms of cost.

H8 The application of the JIT supply chain has a positive impact on a firm's operational performance in terms of product/service quality.

The ILIS is another interface between manufacturer and customer. It enables real-time collaboration and integration among supply chain partners, provides organisations with forward visibility, and improves production planning, inventory management, and distribution. Firms can also develop unique capabilities by establishing information-sharing routines, which result in reduced operating cost and improved productivity, asset efficiency, higher revenues, and improved customer relationships (Patnayakuni et al., 2006). Through managing logistics information in a centralised system, customers can immediately get their required information by one interface. This will greatly improve the perceived service quality. When data and applications in different functions are integrated, manufacturers can improve the smoothness of the production process. Workers can get the required materials whenever and wherever they are needed. This can greatly improve the product reliability and conformance. Centralisation of inventory can help manufacturers optimise their inventory policy from a supply chain perspective. Overall, these efforts will greatly improve production efficiency and reduce total cost.

Therefore, we propose the following hypotheses:

H9 The application of ILIS has a positive impact on a firm's operational performance in terms of cost.

H10 The application of ILIS has a positive impact on a firm's operational performance in terms of product/service quality.

\subsubsection{Operational performance and financial performance}

Some recent studies (Vickery et al., 2003; Narasimhan and Jayaram, 1998), which used both operational and financial performances as indicators for organisational performances, found that operational performance is a good predictor of financial performance. They also suggested that companies should establish a foundation for internal operational performance before pursuing external market performance (Stratman, 2007). Furthermore, when developing taxonomy of manufacturing strategy, Zhao et al. (2006) found that differences in financial performance among Chinese manufacturers can be explained by differences in operational performance.

Therefore, we propose the following hypotheses:

H11 A firm's operational performance in terms of cost has a positive impact on its financial performance.

H12 A firm's operational performance in terms of product/service quality has a positive impact on its financial performance.

As a whole, our conceptual model is shown in Figure 1. 
Figure 1 Conceptual model

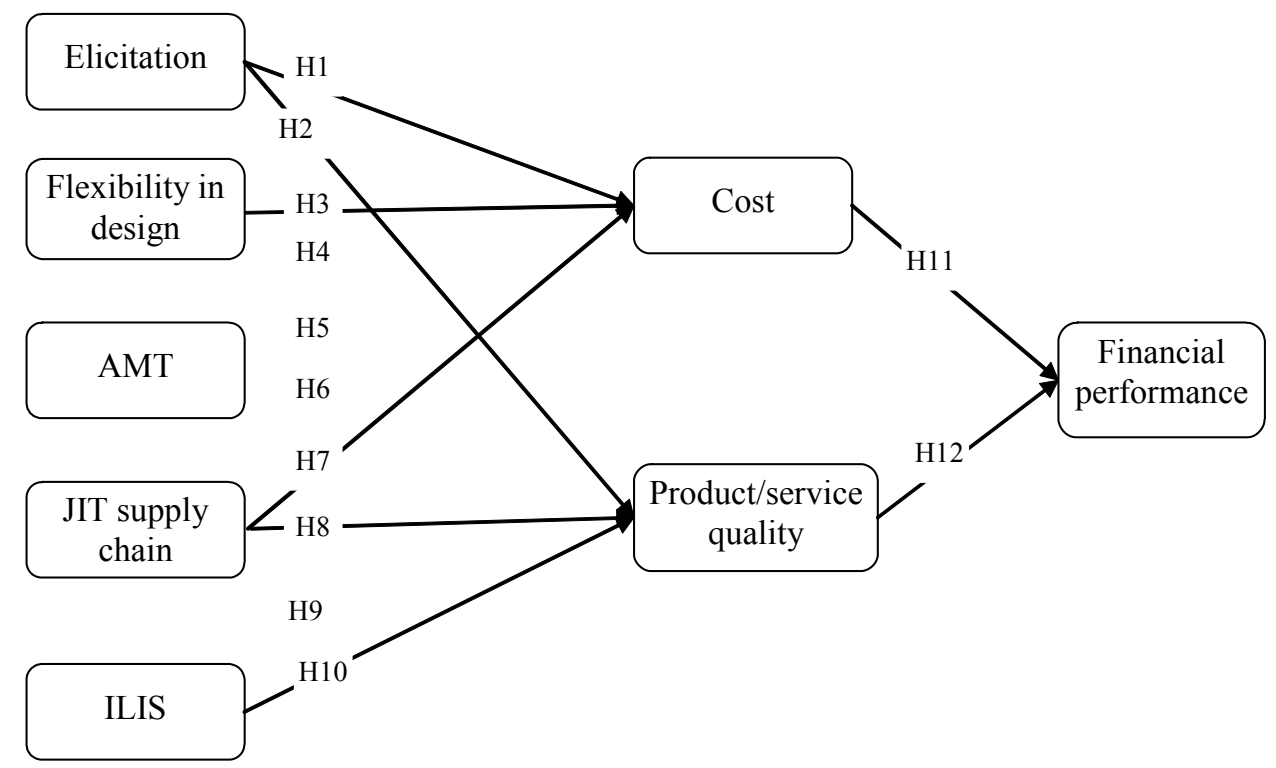

\section{Research methodology}

\subsection{Questionnaire design}

All variables are measured by seven-point Likert scale. With regard to the MC practices items, we asked the informants the following question: 'to what extent does your company use the following practices?' ( $1=$ 'not at all'; $7=$ 'extensively used'). Elicitation is operationalised as relationship building, inter-organisational process improvement, and information sharing with customers through information technology. Flexibility in design is operationalised as the application of postponement and supply chain partner co-design. The AMT is operationalised as the application of computer and information technologies in the whole production process. The JIT supply chain is operationalised as using JIT practices in the whole supply chain to coordinate and synchronise the operations of different partners. The ILIS is operationalised as the integrative management of logistics information. Most items used for the MC practices are results of a thorough review of the literature and the suggestions from both operations management researchers and practitioners (e.g., Berman, 2002; Da Silveira et al., 2001; Feitzinger and Lee, 1997; Pine, 1993; Zipkin, 2001). We measure operational performance based on two aspects: cost and product/service quality. Cost is mainly concerned with manufacturing cost and inventory-related cost because these two kinds of cost constitute the major part of the overall production cost. Meanwhile, product/service quality includes the overall product quality and the manner the firm serves its customers in the whole interaction process, which covers pre-sale, service level, and product support. The customers assess the manufacturers in terms of not only the physical attributes of the products they purchased but also the services they obtain during the purchasing process. All items related to operational performance are extracted from the 
works of Vickery et al. (2003) and Narasimhan and Jayaram (1998). Financial performance is measured by return on investment (ROI), return on sale (ROS), market share, growth in ROI, growth in ROS, and growth in market share (Vickery et al., 2003). For each item, the respondents were asked to rate the performance of their firms compared to their primary competitors over the past three years $(1=$ 'much worse'; $7=$ 'much better'). All measurement items used to address the constructs in this study are listed in the Appendix.

\subsection{Data collection and respondent profile}

The data were collected from China using survey methodology. It is very difficult to obtain samples from all parts of China. So we decided to select three target cities where manufacturing companies are more developed comparing with other areas in the country. They are Beijing (representative of the BSR economic zone and the capital of China), Shanghai (representative of the YRD economic development area), and Guangzhou (representative of the PRD economic development area). When the target cities were determined, we focus on those manufacturing firms with more than 100 employees because manufacturers with less than 100 employees seldom engage in sophisticated manufacturing practices. A total of 9,764 companies met the requirement, with 1,951 from Guangzhou, 5,584 from Shanghai, and 2,229 from Beijing.

Table 1 Demographic statistics

\begin{tabular}{lcc}
\hline & Frequency & Percent (\%) \\
\hline Part A: job title of respondents & 84 & 13.9 \\
General manager & 245 & 40.5 \\
Production and operations manager & 4 & 0.7 \\
SCM and logistics manager & 3 & 0.5 \\
Purchasing and supply manager & 97 & 16.1 \\
Factory director & 58 & 9.6 \\
General manager assistant & 17 & 2.8 \\
CFO & 39 & 6.5 \\
Marketing manager & 27 & 4.5 \\
R\&D manager & 30 & 4.9 \\
Others & 604 & 100 \\
Total & & \\
Part B: years of respondents in the company & & 46.7 \\
$<5$ & 282 & 28.3 \\
5 to 9 & 171 & 13.2 \\
10 to 14 & 80 & 6.0 \\
15 to 19 & 36 & 5.8 \\
$>=20$ & 35 & 100 \\
Total & 604 & \\
\hline
\end{tabular}


A total of 3,187 companies were selected from the database consisting of 9,764 companies, and these were eventually contacted. Out of this number, 463 cannot be contacted because their listed telephone numbers were either incorrect or the company had already changed location or closed down. Of the remaining 2,724 companies, 614 agreed to participate and thereby completed the questionnaire. This generated a response rate of approximately $23 \%$. Ten cases were excluded because of missing values. Table 1 shows the two parts of the demographic statistics on the respondents. As shown in Part A, most of our respondents are general, production, and operations managers. These people therefore, have enough knowledge on operational processes and supply chain management. Part B also shows that most of these respondents have served their own company for five years or more. Thus, the statistics in Table 1 suggest that our respondents are qualified to accomplish the questionnaire, and future survey results are expected to be eligible. Table 2 shows the profiles of the respondent companies with their corresponding number of employees and sales.

Table 2 Sample profile

\begin{tabular}{|c|c|c|c|}
\hline \multicolumn{2}{|c|}{ Annual sales (in million yuan, 1 US\$ $=¥ 8.32 \mathrm{RMB}$ ) } & \multicolumn{2}{|c|}{ Number of employees } \\
\hline Below 5 (0.61 million USD) & $14.4 \%$ & 100 to 199 & $42.7 \%$ \\
\hline 5 to 10 ( 0.61 to 1.22 USD) & 18.2 & 200 to 499 & 41.6 \\
\hline 10 to 30 (1.22 to 3.66 USD) & 34.8 & 500 to 999 & 9.6 \\
\hline 30 to 50 (3.66 to 6.10 USD) & 11.1 & 1,000 to 4,999 & 5.5 \\
\hline 50 to 100 ( 6.10 to 12.20 USD) & 9.9 & 5,000 or more & 0.7 \\
\hline 100 to 250 (12.20 to 30.50 USD) & 4.8 & \multicolumn{2}{|c|}{ Total: $100 \%$} \\
\hline 250 to 500 (30.5 to $61 \mathrm{USD})$ & 3.8 & & \\
\hline 500 to 1,000 ( 61 to 122 USD) & 1.3 & & \\
\hline Above 1,000 (122 USD) & 1.7 & & \\
\hline Total: $100 \%$ & & & \\
\hline
\end{tabular}

A non-response bias test was conducted by checking the differences between the first wave of respondents and later returns (Lambert and Harrington, 1990). T-tests were performed using number of employees, annual sales, ownership type, industry type, and firm's position in the supply chain. The results revealed no significant difference between the two waves of responses, which suggests that there is no significant non-response bias in this study.

Since our data were gathered from a single respondent for one questionnaire, Harman's single-factor test was performed to examine the possibility of common method bias (Podsakoff et al., 2003). All variables are loaded into an exploratory factor analysis (EFA) to check for the unrotated factor solution. The results show that nine factors are presented, and the biggest variance explained is merely $20.81 \%$. We therefore conclude that no single factor emerges from the factor analysis, and no general factor explains most of the variance. Accordingly, there is no serious common method bias in our study. 
The impact of mass customisation practices on performances

Table 3 Factor analysis for manufacturing practices

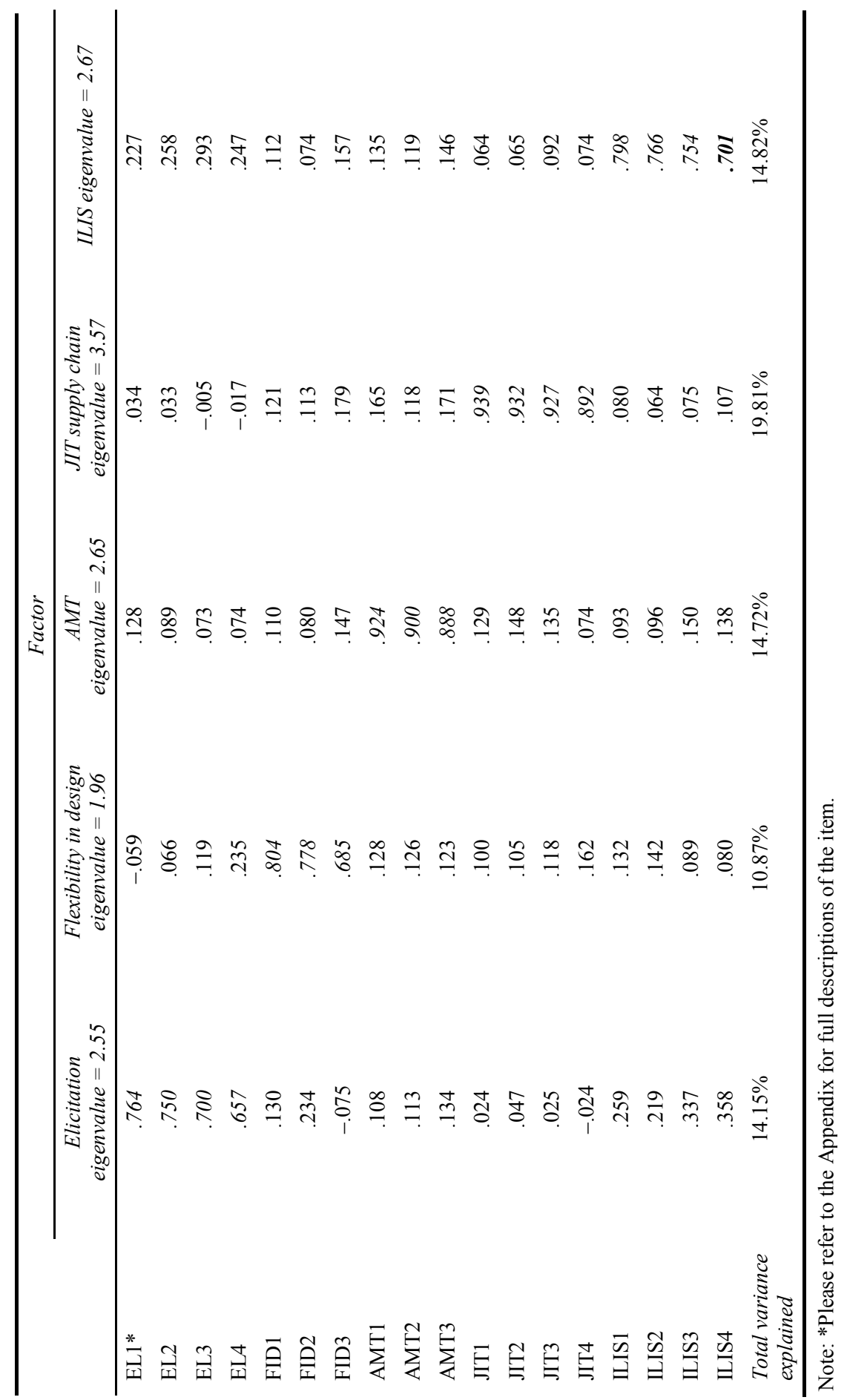




\subsection{Measurement validation}

\subsubsection{Unidimensionality and reliability}

Because our study is one of the first studies conducted in China that focus on MC practices, it is exploratory in some degree. Therefore, measurement validation is important for future studies. First, we conduct EFA to identify the constructs to be used in further analysis. The indicator items are deleted when they are loaded into more than two factors or when their factor loadings are smaller than 0.5 as suggested by Johnson and Wichern (1998). Moreover, the items that did not load into the factor that they were intended to measure but loaded into other factors are also deleted. Tables 3 and 4 show the results of principal component factor analysis with varimax rotation for MC practices, operational performance, and financial performance variables. The tables suggest that all the items are loaded into the specific factor that they are intended to measure. In addition, the factor loadings were also larger than 0.5. Collectively, the above analysis suggested that the factor analysis was appropriately used. The MC system can be classified into elicitation, flexibility in design, AMT, JIT supply chain, and ILIS. Meanwhile, operational performance can be classified into cost and quality/service performance. Financial performance stands out as a single factor. Only one component can be extracted for each construct. The results ensured the unidimensionality of each construct.

Table 4 Factor analysis for performance

\begin{tabular}{|c|c|c|c|}
\hline & \multicolumn{3}{|c|}{ Factor } \\
\hline & $\begin{array}{c}\text { Financial } \\
\text { performance } \\
\text { eigenvalue }=3.98\end{array}$ & $\begin{array}{c}\text { Product/service } \\
\text { quality } \\
\text { eigenvalue }=2.84\end{array}$ & $\begin{array}{c}\text { Cost } \\
\text { eigenvalue }=2.63\end{array}$ \\
\hline FP1* & .821 & .174 & .157 \\
\hline FP2 & .800 & .195 & .171 \\
\hline FP3 & 790 & .219 & .202 \\
\hline FP4 & .759 & .088 & .217 \\
\hline FP5 & .735 & .262 & .189 \\
\hline FP6 & .684 & .106 & .257 \\
\hline PSQ1 & .151 & .827 & .085 \\
\hline PSQ2 & .223 & .814 & .077 \\
\hline PSQ3 & .159 & .804 & .248 \\
\hline PSQ4 & .209 & .702 & .298 \\
\hline $\operatorname{COS} 1$ & .235 & .087 & .738 \\
\hline $\operatorname{COS} 2$ & .108 & .274 & .692 \\
\hline $\cos 3$ & .092 & .147 & .663 \\
\hline COS4 & .378 & .016 & .614 \\
\hline COS5 & .302 & .202 & .614 \\
\hline Total variance explained & $26.50 \%$ & $18.91 \%$ & $17.50 \%$ \\
\hline
\end{tabular}

Note: *Please refer to the Appendix for full descriptions of the item 
Cronbach's alpha should be used to evaluate construct reliability (Flynn et al., 1990). Table 5 shows that the values of cronbach's alpha are larger than 0.70 , which is the threshold value recommended by Flynn et al. (1990). In addition, the corrected item-total correlation (CITC) reliability test is also used (Flynn et al., 1990). In this test, all items for the same construct should be closely related to the underlying latent variable; 0.30 was considered as the lowest acceptable value. Table 3 shows that all CITC values are larger than 0.4. Based on the cronbach's alpha values and CITC values, we concluded that the scales are reliable.

Table 5 Reliability analysis

\begin{tabular}{lccc}
\hline Construct & Number of items & Cronbach's alpha & CITC \\
\hline Elicitation & 4 & 0.78 & $0.54-0.62$ \\
Flexibility in design & 3 & 0.71 & $0.45-0.59$ \\
AMT & 3 & 0.94 & $0.84-0.92$ \\
JIT supply chain & 4 & 0.96 & $0.85-0.92$ \\
ILIS & 4 & 0.85 & $0.65-0.72$ \\
Cost & 5 & 0.77 & $0.47-0.60$ \\
Product/service quality & 4 & 0.85 & $0.64-0.73$ \\
Financial performance & 6 & 0.90 & $0.63-0.78$ \\
\hline
\end{tabular}

\subsubsection{Validity}

The common method for ensuring content validity is the selection of appropriate measurement items from an extensive review of the literature and evaluating those items by practitioners and knowledgeable researchers. In this study, most items are extracted from the previous literature. Suggestions from operations management researchers and practitioners during questionnaire design and pilot test further confirmed the content validity of the constructs.

We use confirmatory factor analysis (CFA) to assess the validity, which is better than the traditional multi-trait-multi-method matrix method (O'Leary-Kelly and Vokurka, 1998). We first constructed the CFA model using the LISREL 8.54 programme. In the model, each item was linked to its corresponding construct, and the covariances among those constructs were freely estimated. The resulting model fit indices are $\chi^{2}(467)=1,067.58(p=0.000)$, non-normed fit index $(\mathrm{NNFI})=0.98$, comparative fit index $(\mathrm{CFI})=0.98$, incremental fit index $(\mathrm{IFI})=0.98$, and root mean square error of approximation (RMSEA $=0.048$ ), which are better than the threshold values recommended by $\mathrm{Hu}$ and Bentler (1998). Generally, a construct which has either a loading of indicators of at least 0.5 , a significant t-value $(t>2.0)$, or both is considered to be convergently valid (Fornell and Larcker, 1981). Our model satisfies this requirement. Therefore, convergent validity is achieved in our study.

We built a constrained CFA model for each possible pair of latent constructs in which the correlations between the paired constructs are fixed to 1 . We then compared this model with the original unconstrained model in which the correlations among constructs are freely estimated. A significant difference of the chi-square statistics between the fixed and unconstrained models would indicate high discriminant validity (Fornell and Larcker, 1981). In our study, most of constructs are discriminant at 0.001 levels. Therefore, discriminant validity is achieved. 


\section{Analysis and results}

The analysis is done by initially calculating the means, standard deviations, and correlations among all constructs as shown in Table 6. In order to find the real mass customisers, we ask the manufacturers to rate their application level of MC using the Likert scale ( $1=$ 'not at all'; 7 = 'extensively used'). Then we use two-step cluster analysis as proposed by Frohlich and Dixon (2001) to determine the mass customisers. The result of the hierarchical cluster analysis suggests that when the application level of MC is used as taxon, two different groups can be identified from the sample. Subsequently, the K-mean cluster analysis is used. The results are shown in Table 7. Out of the 604 manufacturers, 489 are implementing MC in their organisation. We also compare the product characteristics (see Table 7) between the high MC group and the low MC group. ANOVA analysis reveals that the former provides more mass customised products than the latter in terms of quickly changed customers' requirements and demands, shorter new product time-to-market, and more product features (Pine, 1993). This provides some evidences that the manufacturers in high MC groups are really mass customisers.

Table 6 Means, standard deviations and correlations

\begin{tabular}{|c|c|c|c|c|c|c|c|c|}
\hline & $E I T$ & $F I D$ & $A M T$ & $J I T S C$ & ILIS & Cost & $P S Q$ & $F P$ \\
\hline $\begin{array}{l}\text { Flexibility in design } \\
\text { (FID) }\end{array}$ & $.291 * *$ & & & & & & & \\
\hline AMT & $.291 * *$ & $.322^{* *}$ & & & & & & \\
\hline $\begin{array}{l}\text { JIT supply chain } \\
\text { (JIT SC) }\end{array}$ & $.088 *$ & $.320 * *$ & $.313^{* *}$ & & & & & \\
\hline ILIS & $.652 * *$ & $.337 * *$ & $.344^{* *}$ & $.210 * *$ & & & & \\
\hline Cost & $.432 * *$ & $.326^{* *}$ & $.341 * *$ & $.165 * *$ & $.443 * *$ & & & \\
\hline $\begin{array}{l}\text { Product/service } \\
\text { quality (PSQ) }\end{array}$ & $.449 * *$ & $.148 * *$ & $.195^{* *}$ & $.112 * *$ & $.509 * *$ & $.456^{* *}$ & & \\
\hline $\begin{array}{l}\text { Financial } \\
\text { performance }(\mathrm{FP})\end{array}$ & $.333^{* *}$ & $.304 * *$ & $.376^{* *}$ & $.247 * *$ & $.483 * *$ & $.556^{* *}$ & $.460 * *$ & \\
\hline Mean & 5.05 & 4.48 & 4.52 & 3.66 & 5.03 & 4.86 & 5.40 & 4.64 \\
\hline $\mathrm{Sd}$. & 0.92 & 1.18 & 1.64 & 1.68 & 0.97 & 0.80 & 0.93 & 0.90 \\
\hline
\end{tabular}

Notes: EIT means elicitation, $* * p<0.01$ and $* p<0.05$

The hypothesised model in Figure 1 is tested using the sub-sample of 489 mass customisers. Based on the output of LISREL 8.54, the overall model fit indices are as follows: $\chi^{2}(473)=1069.11(p=0.000), \mathrm{NNFI}=0.98, \mathrm{CFI}=0.98$, IFI $=0.98$, and RMSEA $=0.050$, which are better than the threshold values suggested by $\mathrm{Hu}$ and Bentler (1999). Therefore, our model can be accepted. Figure 2 shows the final structural equation model and the standardised coefficients for the significant paths at 0.05 level.

The results show that elicitation positively affects both cost and product/service quality. Therefore, $\mathrm{H} 1$ and $\mathrm{H} 2$ are supported. The two components of process flexibility technology (flexibility in design and AMT) only significantly and positively influence 
cost performance but not product/service quality. Thus, our results only support H3 and H5 but not H4 and H6. However, Figure 2 shows that the JIT supply chain practice does not improve either cost or product/service quality, which means that $\mathrm{H} 7$ and $\mathrm{H} 8$ are not supported. Furthermore, the ILIS has a significant and positive impact on both cost and product/service quality performance. Thus, $\mathrm{H} 9$ and $\mathrm{H} 10$ are supported. Finally, the results in Figure 2 also demonstrate the significant and positive impact of cost and product/service quality performance on the firm's financial performance. Such results implicate that $\mathrm{H} 11$ and $\mathrm{H} 12$ are supported.

Table 7 Results of cluster analysis and ANOVA

\begin{tabular}{|c|c|c|c|}
\hline & \multicolumn{3}{|c|}{ Cluster } \\
\hline & High & Low & Fvalue \\
\hline Application of $\mathrm{MC}$ & $\begin{array}{c}5.00 \\
\text { (s.d. }=0.899)\end{array}$ & $\begin{array}{c}2.43 \\
\text { (s.d. }=0.702)\end{array}$ & $\begin{array}{l}822.338 \\
(p=.000)\end{array}$ \\
\hline Number of cases & 489 & 115 & \\
\hline \multicolumn{4}{|l|}{ Product characteristics } \\
\hline $\begin{array}{l}\text { The new products' } \\
\text { time-to-market is very short }\end{array}$ & $\begin{array}{c}4.43 \\
\text { (s.d. }=1.37)\end{array}$ & $\begin{array}{c}4.10 \\
\text { (s.d. }=1.65)\end{array}$ & $\begin{array}{c}4.725 \\
(p=.030)\end{array}$ \\
\hline $\begin{array}{l}\text { The customer requirements } \\
\text { for products changes very } \\
\text { quickly }\end{array}$ & $\begin{array}{c}4.74 \\
(\text { s.d. }=1.39)\end{array}$ & $\begin{array}{c}4.23 \\
\text { (s.d. }=1.51)\end{array}$ & $\begin{array}{c}11.678 \\
(p=.001)\end{array}$ \\
\hline $\begin{array}{l}\text { The demand of each type of } \\
\text { end product vary quickly }\end{array}$ & $\begin{array}{c}4.42 \\
(\text { s.d. }=1.33)\end{array}$ & $\begin{array}{c}4.15 \\
\text { (s.d. }=1.34)\end{array}$ & $\begin{array}{c}3.853 \\
(p=.050)\end{array}$ \\
\hline $\begin{array}{l}\text { Providing product with many } \\
\text { features }\end{array}$ & $\begin{array}{c}4.99 \\
\text { (s.d. }=1.25)\end{array}$ & $\begin{array}{c}4.43 \\
\text { (s.d. }=1.40)\end{array}$ & $\begin{array}{c}18.342 \\
(p=.000)\end{array}$ \\
\hline
\end{tabular}

Figure 2 Results of structure equation model

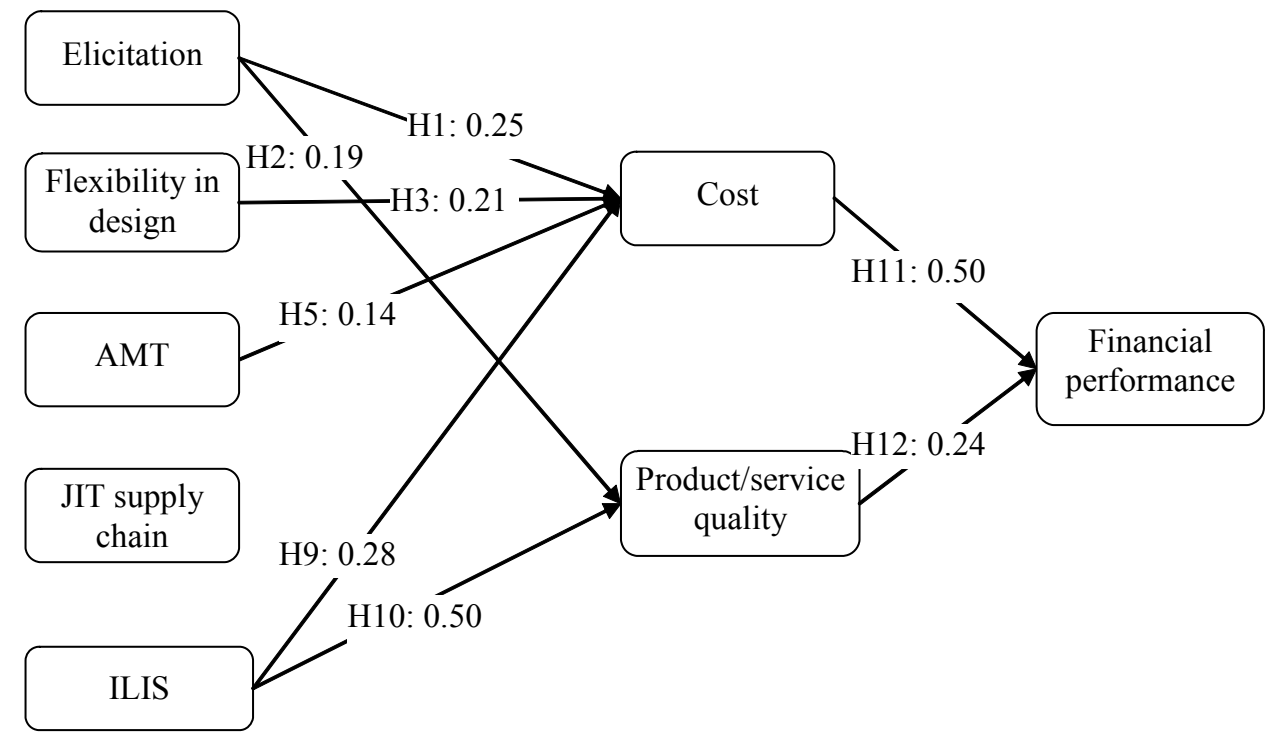




\section{Discussion and conclusions}

Though researchers have proved that manufacturers can improve MC capability through certain manufacturing practices, there is no empirical evidences that can guide the practitioners to redesign the whole manufacturing system to achieve MC. Based on framework proposed by Zipkin (2001), we define the MC system through five kinds of manufacturing practices: elicitation, flexibility in design, AMT, JIT supply chain, and ILIS, which cover the whole product, process, and supply chain design. In particular, the elicitation brings the necessary information for those designs, the flexibility in design and AMT improve the design and manufacturing process, and the JIT supply chain and ILIS focus on the supply chain management.

In this paper, we empirically examine the relationships between this framework and business performance. Generally speaking, we found that MC adopters do not only enjoy lower cost but also provide higher product/service quality and then gain better financial performance compared with their competitors. Moreover, our analysis suggests that each practice has different impacts on different performance indicators. To be specific, we find that flexibility in design and AMT mainly affects the cost performance but not the product/service quality; elicitation and ILIS improve both performance indictors; and JIT supply chain contributes neither of them. These results indicate that the framework proposed by Zipkin (2001) needs to be used carefully when the managers want to transit to $\mathrm{MC}$ and change the manufacturing system in China.

In particular, the process flexible technologies do not improve the product/service quality directly. The reason is that these efforts might affect quality indirectly. Elicitation and ILIS practices provide information input for the manufacturers on how to improve product/service quality. However, the information would be useless to manufacturers if their manufacturing processes are not flexible enough to incorporate them and respond to customers' preferences by redesigning the product and process. Thus, elicitation and ILIS can no longer improve product/service quality without a solid internal foundation. Therefore, as posited by Zipkin (2001), we suggest that managers adopt these practices simultaneously because they are elements of an integrated system and have different impacts on the operational performances. Moreover, these practices describe the entire process of how MC operations create value. Elicitation focuses on obtaining customers' information, which is used by process flexibility technology to transform customers' demands into actual products. The material and information used in the production process are moved along the supply chain, and the finished products are delivered to customers through the logistics system.

The JIT supply chain is not significantly related to any performance indicator. There may be three reasons for this. First, although the logistics industry and transportation infrastructure has been greatly improved in recent years, it is still relatively poor and underdeveloped comparing with developed countries, which will incur the users much higher cost when applying JIT supply chain in China. Second, recognising the reality of underdeveloped logistics infrastructure, customers have been used to the poor delivery performance of manufacturers. Thus, customers do not have high expectations or requirements for delivery from Chinese manufacturers. Third, Zhao et al. (2006) found that Chinese manufacturers are used to put the delivery speed and reliability to lower priority as compared to other priorities. They do not believe that they can get significant returns on investment by improving their delivery capabilities. Jiang and Prater (2002) found that China's distribution system is between the socialist system and the free market 
system. This would mean a substantively high amount of investment in logistics and distribution required by Chinese manufacturers if they want to enhance their delivery performance through an efficient JIT delivery system. As noted in the work of Moradian and Sowinski (2004, p.56), it is "substantially more expensive to transport goods in China than it is in North America or Europe". The added investment might not be sufficiently compensated by new businesses, higher volumes, and higher margins for Chinese manufacturers. Therefore, the application of JIT supply chain has not contributed to the competitive advantage of mass customisers.

This study represents the first attempt to systematically study MC practices and business performance in China, which contributes to the understanding of how Chinese manufacturers use the MC practices. Instead of focusing on the effects of certain manufacturing practices on MC, this study takes a holistic perspective based on an integrated framework. Since the MC requires the manufacturers to change its entire manufacturing system (Pine, 1993; Da Silveira et al., 2001) and the effects of manufacturing practices are related to each other, the integrated view can help the researchers and practitioners understand $\mathrm{MC}$ better. Moreover, we generalise this framework through structural equation modelling and data collected from Chinese manufacturers. The original framework is developed based on the successful western mass customisers. However, there are no empirical explorations of whether this framework can be generalised to the developing market, which has different economic environment. Therefore, we go through the conceptualisation and description of successful industrial examples of MC application to large-scale empirical validation. Furthermore, we found that different MC practices take different roles in performance improvement, which helps the researchers and practitioners understand the nature of $\mathrm{MC}$ practices better.

These evidences can be used to guide manufacturers' decisions when transiting to MC. According to our findings, the manufacturers should be cautious when implementing JIT supply chain in China because it has no direct effect on both cost and product/service quality performances. However, it doesn't mean that JIT supply chain should be neglected. As explained in previous sections, the JIT supply chain is an infrastructure and its benefits is counteracted by the high logistics cost. Furthermore, the most important practices for mass customisers are elicitation and ILIS because they are beneficial in both cost and product/service quality. Therefore, if resources are limited, the mass customisers should put these two sets of practices at the first priority. Next, mass customisers can consider building the capability of design flexibility due to relatively higher impact on performance (path coefficient is 0.21). As a matter of fact, design flexibility is easier to be achieved on the basis of implementing elicitation and ILIS. Finally, mass customisers can choose to invest in the AMT, which are capital intensive. Though our procedure model shows that mass customisers can implement MC practices in some order, we should emphasise that the all the MC practices are complementary in terms of performance impact.

The analysis in this study was done based on data collected in China, which both has its merits and limitations. Frohlich and Dixon (2001) argued that manufacturing strategies vary from country to country because their competitive environments and contexts are different. Furthermore, national culture, institutional and economical environments may also influence the effects of MC. It will therefore be interesting to compare studies about MC practices in China with those in other countries such as the USA, Japan, Korea, and European countries. Another limitation of this study is that our survey data are cross 
sectional. It helps us establish associative relationship. But to build causal relationship, we need to conduct longitudinal or quasi-experimental studies in the future. Last but not least, this study does not consider the prerequisites and boundary conditions for the impact of MC practices on performance. In particular, the effectiveness of MC practices might be affected by other organisational and manufacturing practices. Thus, how these contingencies affect the relationship between MC practices and business performances should also be an interesting topic for future studies.

\section{Acknowledgements}

This research was supported by Centre for Supply Chain Management and Logistics, Li and Fung Institute of Supply Chain Management and Logistics. The authors would also like to acknowledge the General Research Grant Fund from Hong Kong Research Grant Council: CUHK455009.

\section{References}

Ahlstrom, P. and Westbrook, R. (1999) 'Implications of mass customization for operations management: an exploratory survey', International Journal of Operations \& Production Management, Vol. 19, No. 3, pp.262-274.

Berman, B. (2002) 'Should your firm adopt a mass customization strategy?', Business Horizons, July-August, pp.51-60.

Da Silveira, G., Borenstein, D. and Fogliatto, F.S. (2001) 'Mass customization: literature review and research directions', International Journal Production Economics, Vol. 72, No. 1, pp.1-13.

Duray, R., Ward, P.T., Willigan, G.W. and Berry, W.L. (2000) 'Approaches to mass customization: configurations and empirical validation', Journal of Operations Management, Vol.18, No. 6, pp.605-625.

Duray, R. (2006) 'Pursuing capabilities of flexibility and quality: financial performance implications for mass customizers', International Journal of Mass Customisation, Vol. 1, Nos.2/3, pp.260-271.

Feitzinger, E. and Lee, H.L. (1997) 'Mass customization at Hewlett-Packard: the power of postponement', Harvard Business Review, January-February, pp.116-121.

Flynn, B.B., Sakakibara, S., Schroeder, R.G., Bates, K.A. and Flynn, E.J. (1990) 'Empirical research methods in operations management', Journal of Operations Management, Vol. 9, No. 2, pp.250-284.

Fornell, C. and Larcker, D.F. (1981) 'Evaluating structural equation models with unobservable variables and measurement error', Journal of Marketing Research, Vol. 18, No. 1, pp.29-50.

Frohlich, M.T. and Dixon, J.R. (2001) 'A taxonomy of manufacturing strategies revisited', Journal of Operations Management, Vol. 19, No. 5, pp.541-558.

Fullerton, R.R. and McWatters, C.S. (2001) 'The production performance benefits from JIT implementation', Journal of Operations Management, Vol. 19, No. 1, pp.81-96.

Fullerton, R.R., McWatters, C.S. and Fawson, C. (2003) 'An examination of the relationships between JIT and financial performances', Journal of Operations Management, Vol. 21, No. 4, pp.383-404.

Hu, L. and Bentler, P.M. (1999) 'Cutoff criteria for fit indices in covariance structure analysis: conventional criteria versus new alternatives', Structural Equation Modeling, Vol. 6, No. 1, pp.1-55. 
Huang, X., Kristal, M.M. and Schroeder, R.G. (2008) 'Linking learning and effective process implementation to mass customization capabilities', Journal of Operations Management, Vol. 26, No. 6, pp.714-729.

Jiang, B. and Prater, E. (2002) 'Distribution and logistics development in China: the revolution has begun', International Journal of Physical Distribution \& Logistics Management, Vol. 32, No. 9, pp.783-798.

Johnson, R.A. and Wichern, D.W. (1998) Applied Multivariate Statistical Analysis, Prentice-Hall, Englewood Cliffs, NJ.

Lai, F., Li, D., Wang, Q. and Zhao, X. (2008) 'The information technology capability of third-party logistics providers: a resource-based view and empirical evidence from China', Journal of Supply Chain Management, Vol. 44, No. 3, pp.22-38.

Lambert, D.M. and Harrington, T.C. (1990) 'Measuring nonresponse bias in customer service mail surveys', Journal of Business Logistics, Vol. 11, No. 2, pp.5-25.

Liu, G., Shah, R. and Schroeder, R.G. (2006) 'Linking work design to mass customization: a sociotechnical systems perspective', Decision Sciences, Vol. 37, No. 4, pp.519-545.

McDermott, C.M. and Stock, G.N. (1999) 'Organizational culture and advanced manufacturing technology implementation', Journal of Operations Management, Vol. 17, No. 5, pp.521-533.

Moradian, R. and Sowinski, L. (2004) 'The world's 'factory floor' has some rough spots', World Trade, Vol. 17, No. 5, pp.56-58.

Narasimhan, R. and Jayaram, J. (1998) 'An empirical investigation of the antecedence and consequences of manufacturing goal achievement in North American, European and Pan Pacific firms', Journal of Operations Management, Vol. 16, Nos. 2/3, pp.159-176.

O'Leary-Kelly, S.W. and Vokurka, R.J. (1998) 'The empirical assessment of construct validity', Journal of Operations Management, Vol. 16, No. 4, pp.387-405.

Patnayakuni, R., Rai, A. and Seth, N. (2006) 'Relational antecedents of information flow integration for supply chain coordination', Journal of Management Information System, Vol. 23, No. 1, pp.13-49.

Pine, B.J. (1993) Mass Customization: The New Frontier in Business Competition, Harvard Business School Press, Boston, MA.

Petersen, K.J., Handfield, R.B. and Ragatz, G.L. (2005) 'Supplier integration into new product development: coordinating product, process and supply chain design', Journal of Operations Management, Vol. 23, Nos. 3/4, pp.371-388.

Piller, F.T. (2004) 'Mass customization: reflections and the state of the concept', International Journal of Flexible Manufacturing Systems, Vol. 16, No. 7, pp.313-334.

Piller, F.T. and Muller, M. (2004) 'A new marketing approach to mass customization', International Journal of Computer Integrated Manufacturing, Vol. 17, No. 7, pp.583-593.

Piller, F.T. (2005) 'Mass customization in China: China as a market and manufacturing place for customized goods, the example of Youngor', Vol. 8, No. 3, pp.11-12, available at $\mathrm{http}: / /$ www.mass-customization.de/news/newsletter.htm\#2005 (accessed on 20/06/2011).

Podsakoff, P.M., MacKenzie, S.B., Lee, J.Y. and Podsakoff, N.P. (2003) 'Common method bias in behavioral research: a critical review of the literature and recommended remedies', Journal of Applied Psychology, Vol. 88, No. 5, pp.879-903.

Rungtusanatham, M. and Salvador, F. (2008) 'From mass production to mass customization: hindrance factors, structural inertia, and transition hazard', Production and Operations Management, Vol. 17, No. 3, pp.385-396.

Safizadeh, H.M., Ritzman, L.P., Sharma, D. and Wood, C. (1996) 'An empirical analysis of the product-process matrix', Management Science, Vol. 42, No. 11, pp.1576-1592.

Salvador, F., de Holan, P.M. and Piller, F. (2009) 'Cracking the code of mass customization', MIT Sloan Management Review, Vol. 50, No. 3, pp.71-78.

Schroeder, R.G. and Flynn, B. (2001) High Performance Manufacturing: Global Perspectives, John Wiley \& Sons, Inc., New York. 
Stratman, J.K. (2007) 'Realizing benefits form enterprise resource planning: does strategic focus matter?', Production and Operations Management, Vol. 16, No. 2, pp.203-217.

Sugumaran, V., Dietrich, A.J. and Kirn, S. (2006) 'Supporting mass customization with agent-based coordination', Information Systems and E-business Management, Vol. 4, No. 1, pp.83-106.

Tu, Q., Vonderembse, M.A. and Ragu-Nathan, T.S. (2001) 'The impact of time-based manufacturing practices on mass customization and value to customer', Journal of Operations Management, Vol. 19, No. 2, pp.201-217.

Tu, Q., Vonderembse, M.A., Ragu-Nathan, T.S. and Ragu-Nathan, B. (2004) 'Measuring modularity-based manufacturing practices and their impact on mass customization capability: a customer-driven perspective', Decision Sciences, Vol. 35, No. 2, pp.147-167.

Vickery, S.K., Jayaram, J., Doge, C. and Calantine, R. (2003) 'The effects of an integrative supply chain strategy on customer service and financial performance: an analysis of direct versus indirect relationships', Journal of Operations Management, Vol. 21, No. 5, pp.523-539.

Yang, B., Burns, Neil, D. and Backhouse, C.J. (2005) 'The application of postponement in industry', IEEE Transactions on Engineering Management, Vol. 52 No. 2, pp.238-248.

Zhao, X., Sum, C.C., Qi, Y., Zhang, H. and Lee, T.S. (2006) 'A taxonomy of manufacturing strategies in China', Journal of Operations Management, Vol. 24, No. 5, pp.621-636.

Zhao, X., Flynn, B.B. and Roth, A.V. (2007) 'Decision sciences research in China: current status, opportunities, and propositions for research in supply chain management, logistics, and quality management', Decision Sciences, Vol. 38, No. 1, pp.39-80.

Zhang, X. and Chen, R. (2006) 'Forecast-driven or customer-order-driven? An empirical analysis of the Chinese automotive industry', International Journal of Operations \& Production Management, Vol. 26, No. 6, pp.668-688.

Zhang, X. and Ju, Z. (2002) 'Mass customization: the new choice of manufacturing industry in China', Commercial Research, Vol. 239, No. 2, pp.97-99.

Zhao, X., Flynn, B.B. and Roth, A.V. (2007) 'Decision sciences research in China: current status, opportunities, and propositions for research in supply chain management, logistics, and quality management', Decision Sciences, Vol. 38, No. 1, pp.39-80.

Zipkin, P. (2001) 'The limits of mass customization', MIT Sloan Management Review, Spring, Vol. 42, No. 3, pp.81-87.

\section{Notes}

1 Adapted from Luen Thai: Creating a World-class Apparel Supply Chain published by Peking University Luen Thai Center for Supply Chain System R\&D, November 2005.

2 Adapted from Luen Thai: Creating a World-class Apparel Supply Chain published by Peking University Luen Thai Center for Supply Chain System R\&D, November 2005. 


\section{Appendix}

\section{Mass customisation system}

\section{Elicitation}

EL1 creating a greater level of trust with customers

EL2 working with customers to improve inter-organisational processes with customers

EL3 creating linkage with customers through information technology

EL4 sharing information with customers.

Process flexibility technology

- Flexibility in design

FID1 involving suppliers in product development stage

FID2 involving customers in product development stage

FID3 quick response to customers though postponement.

- $\mathrm{AMT}$

AMT1 application of computer/information technology in manufacturing process (e.g., CAM, CIM, FMS, CNC)

AMT2 application of computer technology in product design (e.g., CAD, CAE, CAPP)

AMT3 application of computer/information technology in manufacturing planning and control (e.g., MRPII, ERP).

\section{Logistics}

- JIT supply chain

JIT1 JIT purchasing with your suppliers

JIT2 JIT production and Kanban system

JIT3 JIT delivery with your customers

JIT4 aiding suppliers to increase their JIT capabilities.

- Integrated logistics information system

ILIS1 integrative inventory management

ILIS2 real time integration and connection among all internal functions from raw material management through production, shipping, and sales

ILIS3 enterprise application integration among internal functions

ILIS4 data integration among internal functions. 


\section{Performance}

Financial performance

FP1 growth in ROI

FP2 growth in ROS

FP3 ROI

FP4 growth in market share

FP5 ROS

FP6 market share.

\section{Product/service quality}

PSQ1 Pre-sale customer service

PSQ2 product support

PSQ3 customer service level

PSQ4 overall product quality.

Cost

COS1 inventory turnover

COS2 obsolescence cost

COS3 stockout cost

COS4 unit manufacturing cost

COS5 overall labour productivity. 